\title{
Первые результаты экспериментального электромагнитного зондирования земной коры на полуостровах Средний и Рыбачий
}

\author{
Любчич В.А., Шипилов Э.В., Юрик Р.Ю. \\ ${ }^{1}$ Полярный геофизический институт, Мурманск, lubchich@yandex.ru
}

\begin{abstract}
Аннотация. Работа посвящена изучению строения литосферы и структуры осадочного чехла электромагнитными геофизическими методами полуостровов Рыбачий и Средний. В тектоническом отношении они входят в зону перехода от кристаллического архейского Балтийского щита к Западно-Арктической платформе, что вызывает интерес с точки зрения исследования закономерностей строения литосферы в исследуемой области. В ходе проведения эксперимента FENICS-2019 по электромагнитному зондированию земной коры с помощью промышленных ЛЭП были выполнены измерения электромагнитного поля. По результатам работ были построены геоэлектрические разрезы для верхней части литосферы исследуемого района.
\end{abstract}

Ключевые слова: литосфера, осадочный чехол, электромагнитное зондирование.

\section{The first results of the experimental Earth's crust sounding on the Rybachy and Sredny Peninsulas}

\author{
Lubchich V.A., Shipilov E.V., Yurik R.Yu. \\ ${ }^{1}$ Polar Geophysical Institute, Murmansk, lubchich@yandex.ru
}

\begin{abstract}
The article is devoted to studying the lithosphere and the geological structure of the sedimentary cover of the Rybachy and Sredny Peninsulas by using electromagnetic geophysical methods. This segment of continental margin represents the transition zone from the Archean crystalline Baltic Shield to the West-Arctic platform. In this regard, the investigated area is of interest in terms of solving the problem of determining regularities of changes of the deep structure of the lithosphere in this transition region. During the experimental work in the project FENICS-2019 on electromagnetic sounding of the Earth's crust by using industrial power lines, the measurements of the electromagnetic field were performed. Based on the results of experimental measurements, the geoelectric sections were constructed for the upper part of the lithosphere of the studied area.
\end{abstract}

Key words: lithosphere, sedimentary cover, electromagnetic sounding.

\section{Введение}

В качестве объекта для постановки исследований выбраны полуострова Рыбачий и средний входящие в состав зоны перехода от Восточно-Европейского кратона к Западно-Арктической платформе, что вызывает интерес с точки зрения решения задач изучения закономерностей изменения глубинного строения литосферы в исследуемой области. Эти вопросы всегда относились к фундаментальным проблемам геологической науки и являются актуальными с позиций познания глубинного строения Земли.

В плане экспериментальных исследований переходной области методами электромагнитного зондирования выполненные работы позволяют построить обобщенный геоэлектрический разрез земной коры до глубин порядка 30 км, а также оценить влияние зон тектонических разломов, обладающих повышенной электропроводностью, на результаты интерпретации измеренных данных.

В плане геологической интерпретации полученные данные дают возможность выделения основополагающих границ раздела земной коры, оценки мощности земной коры и характера ее изменчивости в пределах исследуемого района, на основе чего становится возможным составление глубинной модели строения переходной области.

Так как сведения о строении глубинных уровней литосферы до сих пор остаются весьма скудными и во многом предположительными, исследования с использованием метода электромагнитного зондирования с мощным контролируемым источником проведены впервые, и полученные результаты будут иметь большое значение для получения новых знаний о глубинном строении земной коры. В практическом отношении материалы исследований могут быть использованы для обо- 
снования закономерностей образования и размещения полезных ископаемых, в том числе для оценки углеводородного потенциала осадочных бассейнов.

Вместе с тем полученные результаты в дальнейшем позволят более обоснованно подойти к геодинамическим реконструкциям эволюции региона.

\section{Описание эксперимента}

В 2019 году в ходе проведения эксперимента FENICS-2019 по электромагнитному зондированию земной коры Балтийского щита с помощью промышленных ЛЭП расположенных на Кольском полуострове, сотрудниками Полярного геофизического института были выполнены измерения электромагнитного поля в пределах полуостровов Рыбачий и Средний. Основной задачей проведенных экспериментальных работ являлось изучение строения литосферы и структуры осадочного чехла в зоне перехода от Балтийского щита к Западно-Арктической платформе (рис. 1).

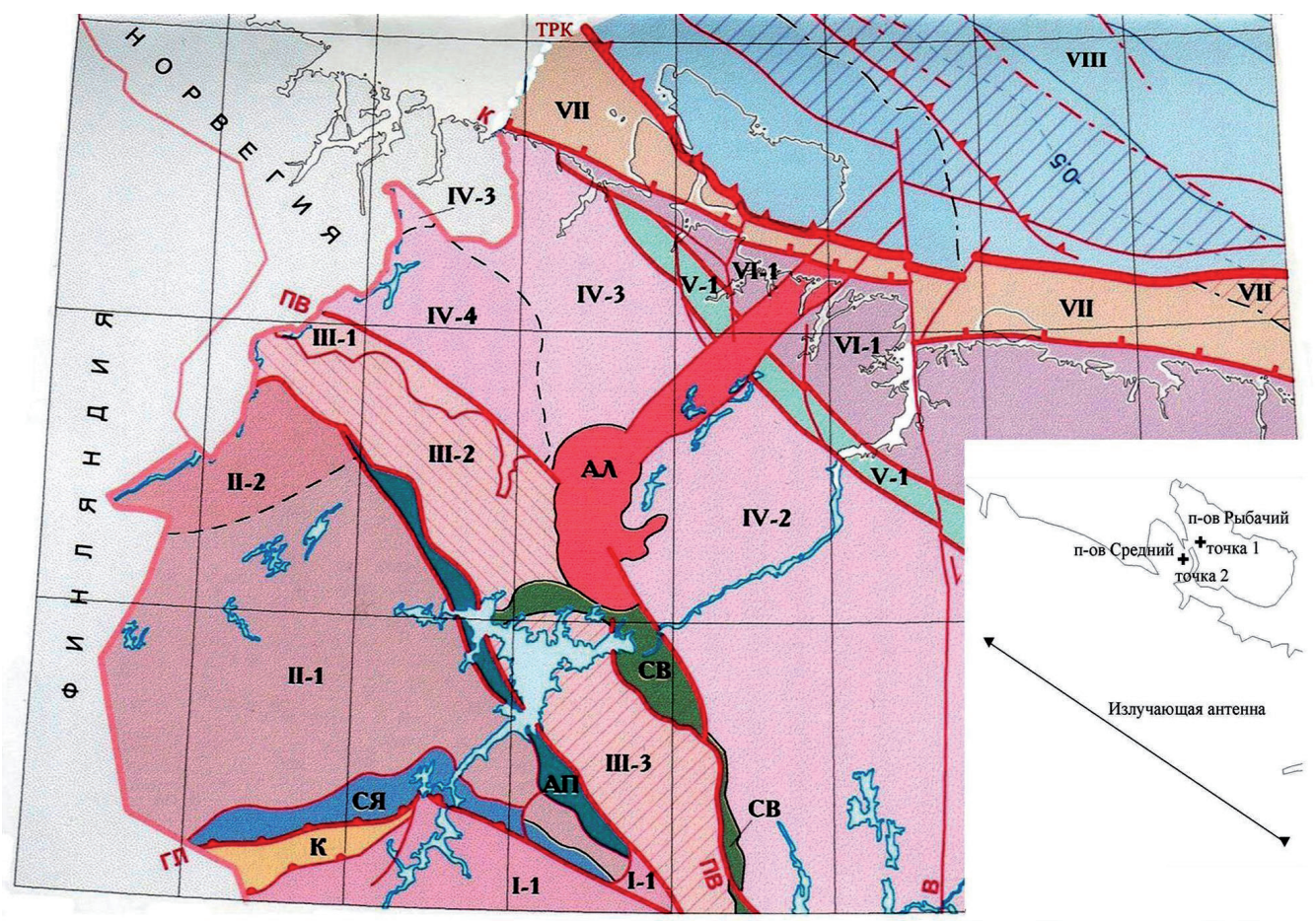

Рис. 1. Схема тектонических элементов Балтийского щита и прилегающей части Западно-Арктической платформы (Шипилов и др., 2017; Шкарубо, Шипилов, 2007). На врезке - схема расположения пунктов регистрации электромагнитного поля и излучающей антенны генератора.

Обозначения на тектонической схеме: Восточно-Европейская платформа. Балтийский щит. I- мегаблок Кольского Беломорья: I-1 - Гирвасский блок; II - Лапландский мегаблок: II-1 - Гранулитовый блок, II-2 - Хихнаярвинский блок; III - Верхнетуломская зона: III-1 - Аллареченско-Солозерский блок, III-2 - Южно-Печенгский блок, III-3 - Нотозерский блок; IV - Центрально-Кольский мегаблок: IV-1 - Чудзьяврский блок, IV-2 - Заимандровский блок, IV-3 - Нясюкский блок, IV-4 - Северо-Печенгский блок; V - Титовско-Поросозерская шовная зона: V-1 - Титовская подзона; VI - Мурманский мегаблок: VI-1 - Северо-Мурманский блок, VI-2 - ЮжноМурманский блок; VII - Кильдинско-Святоносская перикратонная область;

Западно-Арктическая платформа: VIII - Кольско-Финмаркенский мегаблок.

Тектономагматические зоны: СЯ - Сальнотундровско-Яурийокская, К - Корватундровская, СВ - СолозерскоВолчьеозерская, Аккаярви-Пыршинская, АЛ - Ара-Лицкая. Разломы и нарушения: ГЛ - Главный Лапландский надвиг, ПВ - Пороярви-Волчетундровский шов, К - сброс Карпинского, ТРК - линеамент ТроллефьордРыбачий-Кильдин (сдвиго-надвиг), В - Волшепахский сдвиг.

Fig. 1. The scheme of tectonic elements of the Baltic Shield and the adjacent part of the West Arctic Platform (Shipilov et al., 2017; Shkarubo, Shipilov, 2007). The inset shows the location of the electromagnetic field registration points and the transmitting antenna of the generator. 
В качестве одной из антенн контролируемого источника электромагнитных волн использовалась промышленная ЛЭП длиной 130 км, имеющая субширотную ориентацию. В данной линии генерировались электромагнитные поля в интервале частот 0.382-94.22 Гц. В качестве контролируемого источника электромагнитного поля использовался экспериментальный образец мощного генератора, разработанный в ПГИ (Терещенко Е.Д. и др., 2008). Измерения электромагнитных полей производилось в двух пунктах, расположенных в южной части полуострова Рыбачий и на полуострове Средний в окрестности буровой скважины «Пограничная-1». Схема расположения пунктов регистрации электромагнитного поля и излучающей антенны генератора приведена на рисунке 1. С помощью индукционного магнитометра, разработанного в ПГИ, на поверхности Земли измерялись взаимно ортогональные горизонтальные магнитные и электрические компоненты поля. За ось Х принято направление на север вдоль магнитного меридиана. Длина приемных электрических антенн составляла 100 м. Аналоговые сигналы с магнитных датчиков и приемных электрических линий обрабатывались цифровой системой регистрации и сбора данных, основанной на шестиканальном 22-битном аналого-цифровом преобразователе с частотой дискретизации 1024 Гц (Филатов М.В. и др., 2011). Данная система регистрации и сбора данных обеспечивает привязку измерений к мировому времени по сигналам спутниковых навигационных систем ГЛОНАCC/GPS.

Экспериментально измеренные значения отношения амплитуды полного горизонтального электрического поля к полному горизонтальному магнитному полю были пересчитаны через кривые нормального поля в значения кажущегося сопротивления среды. Графики зависимости кажущегося сопротивления $\rho_{k}$ от частоты $f$ представлены на рисунке 2 .

\section{Обсуждение результатов эксперимента}

Полученная для пункта регистрации на полуострове Рыбачий кривая кажущегося сопротивления (рис. 2 а) соответствует трехслойной среде с наличием проводящего слоя, расположенного между высокоомным фундаментом и слоем с относительно повышенным удельным сопротивлением в верхней части разреза. Данная кривая зависимости кажущегося сопротивления от частоты электро-

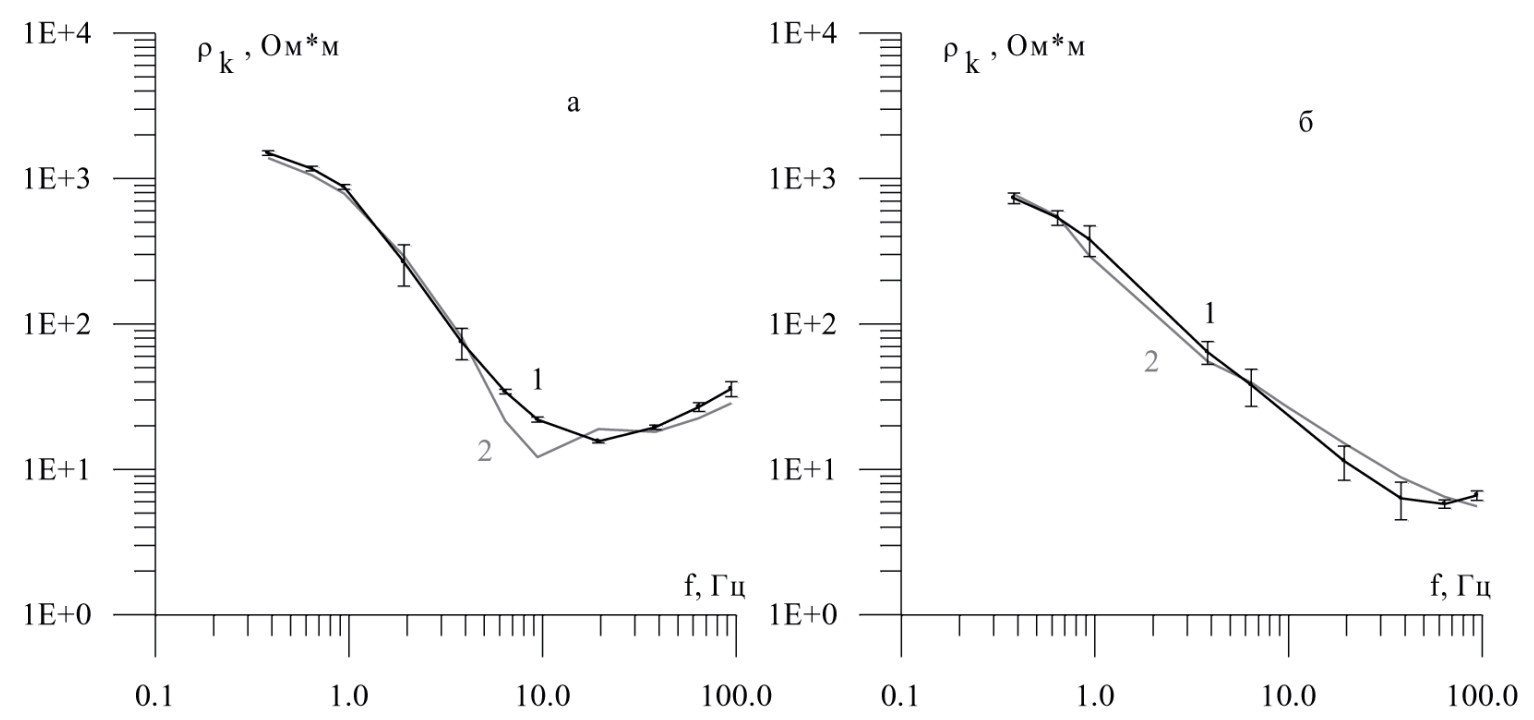

Рис. 2. Графики зависимости кажущегося сопротивления $\rho_{k}$ от частоты электромагнитного поля $f: \mathrm{a}-$ для точки наблюдения на полуострове Рыбачий, б - для точки наблюдения на полуострове Средний. Кривая 1 соответствует экспериментально измеренным данным, кривая 2 соответствует теоретически рассчитанным данным по результатам модельных вычислений.

Fig. 2. Graphs of the dependence of the apparent resistance $\rho_{k}$ on the frequency of electromagnetic field: $\mathrm{a}-$ for the registration point on the Rybachy Peninsula, $b$ - for the registration point on the Sredny Peninsula. Curve 1 corresponds to experimentally measured data, and curve 2 corresponds to data based on the results of model calculations. 
a

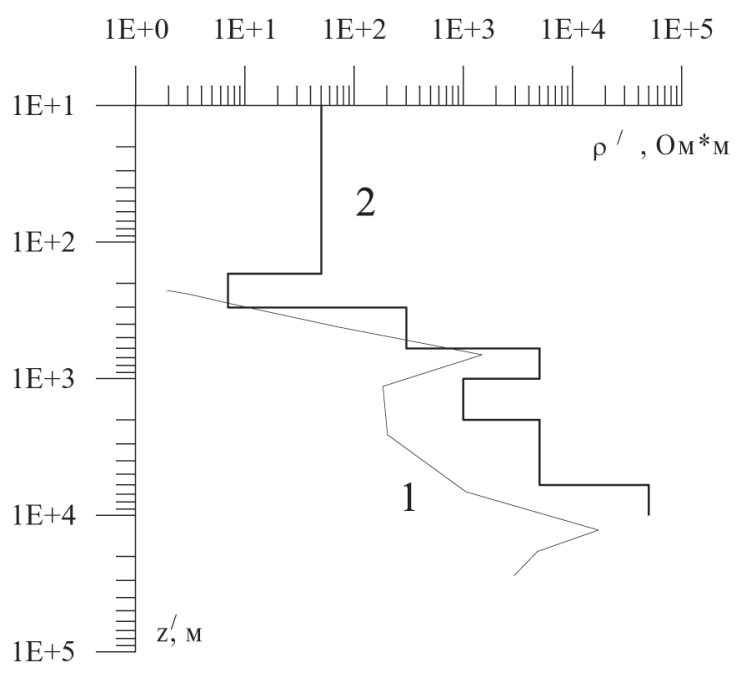

б

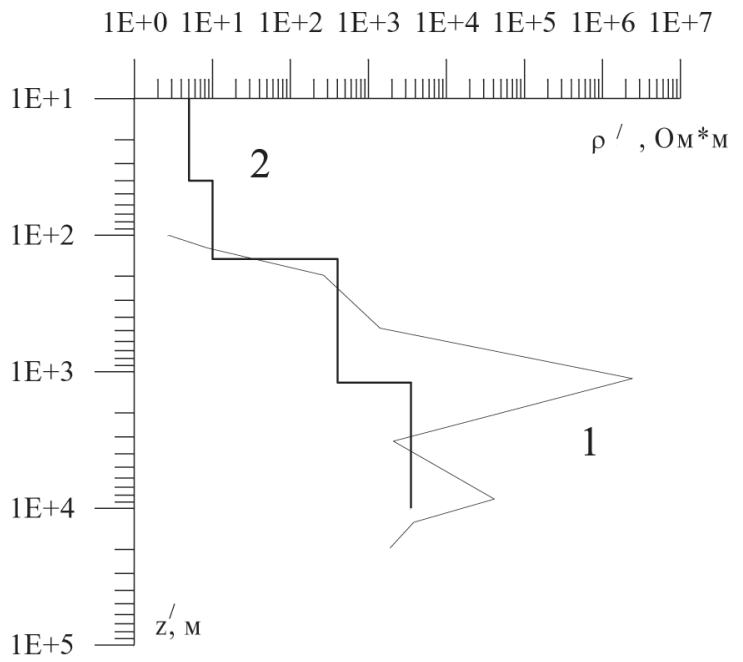

Рис. 3. Графики зависимости действующего сопротивления среды $\rho$ ' от действующей глубины z', построенные по результатам дифференциальной трансформации Молочного-Ле Вьета (кривые 1), и подобранные одномерные модели геоэлектрического разреза среды (кривые 2): а - для точки наблюдения на полуострове Рыбачий, б - для точки наблюдения на полуострове Средний.

Fig. 3. Graphs of the dependence of the effective resistance of the medium $\rho$ ' on the effective depth $z$ ', obtained from the results of the differential Molochnov-Le Viette transformation (curves 1), and selected one-dimensional models of the geoelectric section of the medium (curves 2) : a - for the registration point on the Rybachy Peninsula, $b-$ for the registration point on the Sredny Peninsula.

магнитного поля была трансформирована в график зависимости действующего сопротивления среды $\rho^{\prime}$ от действующей глубины z' с помощью дифференциальной трансформации Молочного-Ле Вьета:

$$
\begin{aligned}
& z^{\prime}=\sqrt{\rho_{k} /(\omega \mu)} \\
& \rho^{\prime}\left(z^{\prime}\right)=\rho_{k} *(1+m / 2)^{2} \\
& \rho^{\prime}\left(z^{\prime}\right)=\rho_{k} /(1-m / 2)^{2}
\end{aligned}
$$

для нисходящей ветви кривой $\rho_{k}$; для восходящей ветви кривой $\rho_{k}$,

где параметр $m$ определяется наклоном кривой кажущегося сопротивления в двойном логарифмическом масштабе

$$
m=\frac{d \log \rho_{k}}{d \log \sqrt{1 / f}}
$$

Применение дифференциальной трансформации Молочного-Ле Вьета к полученным экспериментальным данным является достаточно формальным, так как на низких частотах не выполняется условие аппроксимации электромагнитного поля плоской волной. Но для верхней части геоэлектрического разреза, представленной низкоомным осадочным чехлом, такая трансформация является оправданной и может дать важную информацию о литологическом строении и мощности осадочного чехла.

На рисунке 3 а представлены результаты дифференциальной трансформации Молочного-Ле Вьета для экспериментальной точки, расположенной на полуострове Рыбачий. Из рисунка видно, что на глубине порядка 670 м наблюдается максимум действующего сопротивления среды, с дальнейшим ростом глубины просматривается понижение действующего сопротивления, а с глубины порядка 6 км отмечается повышение сопротивления, вероятно обусловленное влиянием кристаллического фундамента. 
Также на рисунке 3 а приведена подобранная одномерная геоэлектрическая модель среды, состоящая из проводящего верхнего слоя до глубины 600 м с сопротивлением порядка 7-300 Ом·м, относительно высокоомного слоя с сопротивлением 5000 Ом'м в пределах глубин 600-1000 м, слоя с относительно пониженным сопротивлением 1000 Ом'м в пределах глубин 1000-2000 м, слоя с сопротивлением 5000 Ом·м в пределах глубин 2000-6000 м и высокоомного основания с сопротивлением 50000 Ом'м. На рисунке 2 а приведена соответствующая теоретическая кривая кажущегося сопротивления (кривая 2) для подобранной модели среды, которая хорошо совпадает с экспериментально полученной кривой кажущегося сопротивления (кривая 1).

Полученные результаты согласуются с геоэлектрической моделью земной коры на полуострове Рыбачий, построенной в процессе 2D инверсии данных AMT3 и представленной в работе (Сараев А.К. и др., 2011). В этой модели для южной части полуострова граница фундамента расположена на глубине 5-6 км.

Кривая кажущегося сопротивления для экспериментальной точки на полуострове Средний, представленная на рисунке 26 , более соответствует двухслойной кривой, где верхний слой с повышенной электропроводностью расположен над плохо проводящим фундаментом. Дифференциальная трансформация Молочного-Ле Вьета данной кривой, результаты которой представлены на (рис. 3 б), демонстрирует резкий скачок действующего сопротивления среды на глубине порядка 1100 м. Данный скачок можно объяснить влиянием кристаллического фундамента. На этой же глубине скважина «Пограничная-1» вошла в породы кристаллического фундамента (Куликов Н.В. и др., 2007).

На рисунке 3 б представлена также подобранная одномерная геоэлектрическая модель среды, состоящая из низкоомного верхнего слоя до глубины 1200 м с сопротивлением порядка 5-400 Ом· и относительно высокоомного основания с сопротивлением 3500 Ом'м. На рисунке 26 представлена соответствующая модели рассчитанная кривая кажущегося сопротивления (кривая 2), согласующаяся с экспериментальной кривой кажущегося сопротивления (кривая 1).

Таким образом, можно сделать вывод о том, что использование мощных контролируемых источников электромагнитного поля позволяет получать вполне конкретные параметры геоэлектрического строения земной коры в переходной зоне от кристаллического Балтийского щита к ЗападноАрктической платформе, характеризующейся довольно сложным строением и к тому же при наличии мощного низкоомного осадочного чехла.

Работа выполнена в рамках госзадания темы НИР № 0227-2019-0001 и частично поддержана из средств гранта РФФИ (17-45-510956).

\section{Литература}

1. Куликов Н.В., Коновалов В.А., Медведев С.А., Чигвинцев В.Д. Новые данные о геологическом строении севера Кольского полуострова // Разведка и охрана недр. 2007. № 4. С. 22-25.

2. Сараев А.К., Никифоров А.Б., Романова Н.Е., Еремин И.С. Изучение геоэлектрического строения п-ова Рыбачий (Мурманская обл.) по данным аудиомагнитотеллурических зондирований с бесконтактными электрическими антеннами // Вопросы геофизики. Вып. 44. СПб. (Ученые записки СПбГУ; № 444). 2011. С. $133-147$.

3. Терещенко Е.Д., Григорьев В.Ф., Баранник М.Б., Данилин А.Н., Ефимов Б.В., Колобов В.В., Прокопчук П.И., Селиванов В.Н., Копытенко Ю.А., Жамалетдинов А.А. Повышающий преобразователь и система энергопередачи генератора «Энергия-2» для электромагнитных зондирований и мониторинга очаговых зон землетрясений // Сейсмические приборы. 2008. Т. 44. № 4. С. $43-66$.

4. Филатов М.В., Пильгаев С.В., Федоренко Ю.В. Четырехканальный 24-разрядный синхронизированный с мировым временем аналого-цифровой преобразователь // Приборы и техника эксперимента. 2011. № 3. С. 73-75.

5. Шипилов Э.В., Шкарубо С.И., Ковальчук Е.А. Структура и литологический состав разреза отложений Кольского залива (фиорда) по данным бурения и сейсмоакустики и неотектонические условия его формирования // Арктика: экология и экономика. 2017. № 4 (28). С. 72-82. DOI: 10.25283/2223-4594-2017-4-72-82.

6. Шкарубо С.И., Шипилов Э.В. Тектоника Западно-Арктической платформы // Разведка и охрана недр. 2007. № 9. С. 32-47. 